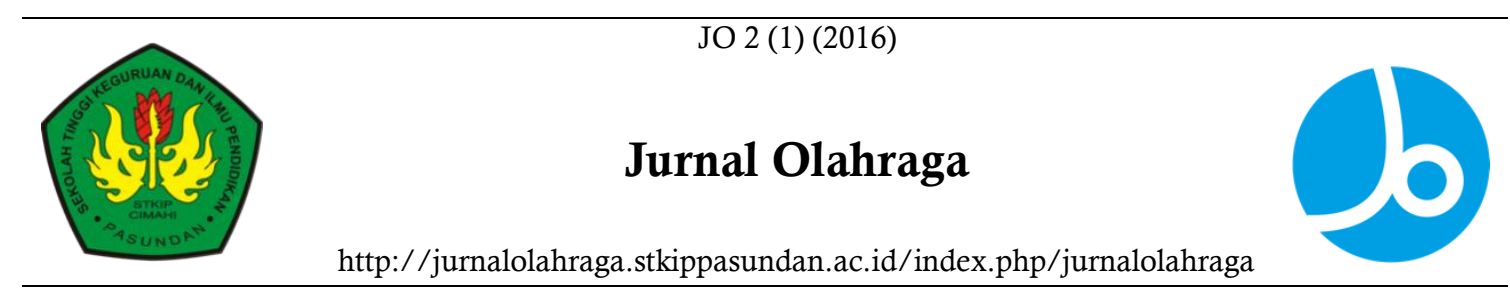

\title{
Keterampilan Shooting Freethrow
}

\author{
Rama Adha Septiana \\ STKIP Pasundan, Indonesia
}

\section{Info Artikel}

Sejarah Artikel:

Diterima Januari 2016

Disetujui Maret 2016

Dipublikasikan April 2016

Keywords:

flesksibilitas pergelangan tangan,

koordinasi mata tangan, percaya

diri, shooting freethrow

\begin{abstract}
Abstrak
Tujuan penelitian ini untuk mengetahui hubungan antara fleksibilitas pergelangan tangan,koordinasi mata-tangan, dan percaya diri pada keterampilan shooting freethrow bola basket Metode penelitian yang digunakan dalam penelitian ini adalah korelasional. Sampel adalah mahasiswa yang mengikuti unit kegiatan mahasiswa sebanyak 28 orang. Variabel bebas adalah fleksibilitas pergelangan tangan $\left(\mathrm{X}_{1}\right)$, koordinasi maa tangan $\left(\mathrm{X}_{2}\right)$, dan percaya diri $\left(\mathrm{X}_{3}\right)$. Sedangkan variabel terikatnya adalah keterampilan shooting pada bola basket (Y). Hasil penelitian menunjukan bahwa pertama adanya hubungan yang signifikan antara $\mathrm{X}_{1}$ dengan $\mathrm{Y}$, koefisien korelasinya adalah 0,530 dengan nilai signifikansi 0,000 .Kedua adanya hubungan yang signifikan antara $\mathrm{X}_{2}$ dengan $\mathrm{Y}$, koefisien korelasinya adalah 0,528 dengan nilai signifikansi 0,000 . Ketiga adanya hubungan yang signifikan antara $\mathrm{X}_{3}$ dengan $\mathrm{Y}$, koefisien korelasinya 0,566 dengan nilai signifikansi 0,0002 .Keempat adanya hubungan yang signifikan antara $\mathrm{X}_{1}, \mathrm{X}_{2}, \mathrm{X}_{3}$ secara bersama-sama dengan $\mathrm{Y}$, koefisien korelasinya adalah sebesar 28,799 dan 2,725 Berdasarkan hasil penelitian dapat disimpulkan bahwa fleksibilitas pergelangan tangan,koordinasi mata-tangan, dan percaya diri berhubungan secara signifikan dengan keterampilan shooting freethrow bola basket. Untuk itu atlet harus melakukan latihan-latihan yang dapat meningkatkan fleksibilitas pergelangan tangan,koordinasi mata-tangan, dan percaya diri yang tinggi agar dapat meningkatkan keterampilan shooting freethrow bola basket
\end{abstract}

\begin{abstract}
The purpose of this study was to determine the relationship between wrist flexibility, eye-hand coordination, and confidence in basketball freethrow shooting skills. The research method used in this study is correlational. Samples were 28 students who took part in student activity units. The independent variables are wrist flexibility (XI), hand coordination (X2), and confidence (X3). While the dependent variable is shooting skills on basketball $(Y)$. The results showed that first there was a significant relationship between $X 1$ and $Y$, the
\end{abstract}


correlation coefficient was 0.530 with a significance value of 0,000 . Second, there was a significant relationship between $X 2$ and $Y$, the correlation coefficient was 0.528 with a significance value of 0,000 . Third, there is a significant relationship between $X 3$ and $Y$, the correlation coefficient is 0.566 with a significance value of 0.0002 . Fourth, there is a significant relationship between X1, X2, X3 together with $Y$, the correlation coefficient is 28.799 and 2.725 Based on the results of the study it can be concluded that wrist flexibility, eye-hand coordination, and self-confidence are significantly related to basketball freethrow shooting skills. For this reason, athletes must do exercises that can increase wrist flexibility, eye-hand coordination, and high confidence in order to improve basketball freethrow shooting skills.

(C) 2016 Rama Adha Septiana Under the license CC BY-SA 4.0

Alamat korespondensi:

E-mail: ramaadha7@gmail.com

ISSN 2442-9961 (cetak)

\section{PENDAHULUAN}

Olahraga pada masa sekarang tidak hanya penting untuk meningkatkan kualitas hidup, tetapi juga untuk meningkatkan prestasi suatu Negara. Dengan memasyarakatkan olahraga dan mengolahragakan masyarakat diharapkan dapat menjadi salah satu unsur pendukung terciptanya pembangunan Nasional. Dengan memasyarakatnya olahraga pada zaman sekarang Bola basket semakin diketahui oleh kebanyakan masyarakat, permainan bola basket juga dapat dimainkan oleh pria maupun wanita dari segala usia dan ukuran tubuh bahkan oleh mereka yang kekurangan dalam hal fisik. Bola basket ditemukan sebagai olahraga dalam ruangan (indoor sport) dan sekarang dimainkan baik di dalam maupun luar ruangan. Permainan bola basket dapat menimbulkan rasa puas bagi orang yang melihatnya, apabila dalam permainan tersebut pemain mampu bermain dengan balk, melakukan teknik-teknik permainan dengan benar, disertai kerja sama antar pemain dalam satu tim yang balk, membuat tim akan lebih tangguh dan susah untuk dikalahkan.

Oleh karena itu untuk bisa bermain bola basket harus menguasai teknik bermain bola basket dan untuk dapat melakukan permainan bola basket, seseorang harus menguasai teknik-teknik dasar bermain bola basket dengan baik secara individu. Bola basket bukan permainan tim saja tetapi juga merupakan permainan yang membutuhkan keterampilan individual. Bola basket adalah olahraga yang dimainkan oleh dua regu, dan saling memasukkan bola ke keranjang lawan dengan tangan. Permainan ini diciptakan oleh Prof. James Naismith seorang instruktur pendidikan jasmani pada YMCA (Young Mens Christian Association), Springfield, Massachusets, Amerika Serikat tahun 1891. Ada beberapa teknik dasar yang perlu dikuasai oleh pemain bola basket seperti yang di tulis dalam buku dasar-dasar bola basket yaitu :

1. Stance (bentuk tubuh) 


\section{Pivot (perputaran)}

\section{Ballhandling (Penguasaan bola)}

4. Passing dan cathing (mengumpan dan menangkap)

\section{Shooting (menembak)}

6. Lay up shoot

\section{Driblling}

Shoot terdiri dari bermacam-macam teknik, antara lain jump shoot, lay up, under ring, dan semua macam gerakan dengan upaya memasukkan bola ke dalam ring merupakan sebuah shoot (menembak) tembakan. Kelentukan (flexibiliy) seseorang sangat menunjang keefektifan seseorang dalam permainan bola basket, sebagai penyesuaian dirinya untuk melakukan segala aktifitas tubuh dengan melakukan penguluran seluas-luasnya terutama otot-otot ligament di sekitar persendian.

Selain itu dibutuhkan pula koordinasi yang baik antara mata untuk melihat ke sasaran dan tangan untuk melemparkan bola, sehingga bola bisa masuk ke ring karena letak ring yang cukup tinggi dan berdiameter kecil. Dalam permainan bola basket di Indonesia, shoot merupakan tembakan yang biasanya dilakukan oleh pemain pada setiap pertandingan, terutama dalam free throw yang dimana hanya dapat dilakukan dengan cara shooting, selain itu tembakan ini memerlukan kelentukan yang baik pada bagian lengan, pergelangan kaki dan tangan, dan jari tangan. Salah satu tembakan yang sering dilakukan oleh pemain bola basket adalah tembakan (shooting). Selain fleksibilitas dan koordinasi antara mata dan tangan, follow though juga berperan dalam permainan bola basket agar dalam memasukkan bola, pemain memiliki kekuatan untuk melemparkan bola sehingga dapat masuk ke dalam ring dengan tepat. Dengan kata lain, fleksibilitas, koordinasi matatangan dan fleksibilitas pergelangan tangan dapat berpengaruh dalam melakukan tembakan ke arah ring agar dalam melakukan gerakan tembakan dapat dilakukan dengan seefektif mungkin dan menghasilkan angka. Definisi koordinasi adalah prilaku dua atau lebih dari komponen kondisi fisik yang satu sama lainnya berkaitan untuk menghasilkan suatu gerak".

Selain hal hal diatas masih ada yang perlu diperhatikan dalam keberhasilan melakukan gerakan shooting bola basket, yaitu tentang rasa percaya diri. orang yang mempunyai kepercayaan diri bagus, mereka memiliki perasaan positif terhadap dirinya, punya keyakinan yang kuat atas dirinya dan punya pengetahuan akurat terhadap kemampuan yang dimiliki. Orang yang punya kepercayaan diri bagus bukanlah orang yang hanya merasa mampu (tetapi sebetulnya tidak mampu) melainkan adalah orang yang mengetahui bahwa dirinya mampu berdasarkan pengalaman dan perhitungannya.

Kepercayaan diri dalam olahraga seperti di jelaskan Vealey dalam Komar bahwa " sport confidence was defined as the degree of certainty individual possess about their ability to be successful in sport. Sport confidence is a more general conceptualization of self confidence". Berdasarkan latar belakang yang telah dikemukakan di atas maka peneliti tertarik apakah ada hubungan antara fleksibilitas pergelangan tangan, koordinasi mata-tangan dan rasa percaya diri pada kererampilan shooting free throw bola basket.

\section{METODE}

Metode penelitian yang di gunakan dalam penelitian ini adalah metode diskriptif dengan studi korelasional, dengan menggunakan analisis regresi ganda yang bertujuan untuk mengetahui ada tidaknya hubungan Fleksibilitas Pergelangan Tangan, koordinasi mata-tangan, dan percaya diri terhadap keterampilan Shooting Freethrow. Serta menjelaskan hubungan setiap variabel bebas dengan variabel terikat balk secara tersendiri-sendiri maupun bersama-sama. adapun pola hubungan antara variabel bebas 
dengan variabel terikat dapat digambarkan sebagai berikut.

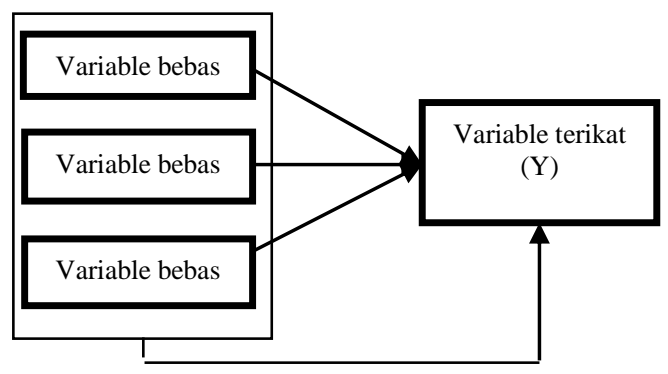

\section{Gambar 1. pola hubungan variable penelitian}

Populasi dalam penelitian ini adalah mahasiswa Unit Kegiatan Mahasiswa STKIP Pasundan. Sampel yang digunakan dalam penelitian ini berjumlah 30 dari populasi keseluruhan (total sampling). Berdasarkan rancangan penelitian di atas maka terdapat empat data yang harus dikumpulkan yaitu: 1) Data tentang keterampilan Shooting Freethrow, 2) Data fleksibilitas pergelangan tangan, 3) Data tentang koordinasi matatangan dengan menggunakan tes, dan 4) Data tentang percaya diri, dengan menggunakan kuisioner.

Pengumpulan data menggunakan instrumen tes penelitian yang telah ditentukan oleh peneliti, dan telah di uji coba terlebih dahulu untuk dapat diketahui tingkat validitas dan reliabilitas tesnya. Instrumen dalam penelitian ini terdiri dari 4 jenis, yaitu instrumen keterampilan shooting free throw, instrumen fleksibilitas pergelangan tangan, instrumen koordinasi mata-tangan, instrumen tes rasa percaya diri.

\section{HASIL DAN PEMBAHASAN}

Hasil data penelitian dimulai dari setiap variabel disajikan dan disusun berdasarkan skor tertinggi, skor terendah, rata-rata ( ) mean dan standar deviasi (SD). Selanjutanya disajikan dalam bentuk tabel distribusi frekuensi dan diagram batang berdasarkan hasil penelitian yang sudah diperoleh.
1. fleksibilitas pergelangan tangan

Distribusi frekuensi skor fleksibilitas pergelangan tangan dari 28 responden diperlihatkan dalam tabel berikut.

tabel 1. Distribusi Frekuensi Skor

Fleksibilitas Pergelangan Tangan

\begin{tabular}{|c|c|c|c|c|c|}
\hline \multirow{2}{*}{$\begin{array}{l}\text { Interv } \\
\text { al }\end{array}$} & \multicolumn{2}{|c|}{$\begin{array}{l}\text { Batas } \\
\text { Interval }\end{array}$} & \multirow{2}{*}{$\begin{array}{l}\text { Frekuen } \\
\text { si }\end{array}$} & \multirow{2}{*}{$\begin{array}{l}\text { Frekuensi } \\
\text { Relatif } \\
(\%)\end{array}$} & \multirow{2}{*}{$\begin{array}{l}\text { Frekuen } \\
\text { si } \\
\text { Komulat } \\
\text { if } \\
(\%)\end{array}$} \\
\hline & $\begin{array}{l}\text { Bawa } \\
h\end{array}$ & $\begin{array}{l}\text { Ata } \\
\mathrm{s}\end{array}$ & & & \\
\hline $70-75$ & 69.5 & $\begin{array}{l}75 . \\
5\end{array}$ & 8 & $29 \%$ & $29 \%$ \\
\hline $76-80$ & 75.5 & $\begin{array}{l}80 . \\
5\end{array}$ & 7 & $25 \%$ & $54 \%$ \\
\hline $81-85$ & 80.5 & $\begin{array}{l}85 . \\
5\end{array}$ & 5 & $18 \%$ & $71 \%$ \\
\hline
\end{tabular}

\begin{tabular}{|c|c|c|c|c|c|c|c|}
\hline \multirow{2}{*}{0} & \multirow{2}{*}{\multicolumn{2}{|c|}{ Analisis Data }} & \multicolumn{5}{|c|}{ Variabel } \\
\hline & & & \multicolumn{2}{|c|}{$\mathrm{X} 1$} & $\mathrm{X} 2$ & X3 & $\mathrm{Y}$ \\
\hline 1 & \multicolumn{2}{|c|}{ Rata-rata } & \multicolumn{2}{|c|}{15.39} & 3.53 & 117.89 & 39.78 \\
\hline 2 & \multicolumn{2}{|c|}{ Modus } & \multicolumn{2}{|l|}{-} & - & 102 & - \\
\hline 3 & \multicolumn{2}{|c|}{ Median } & \multicolumn{2}{|c|}{15.44} & 3.54 & 116 & 39.725 \\
\hline 4 & \multicolumn{2}{|c|}{ Standar Deviasi } & \multicolumn{2}{|c|}{2.35} & 0.33 & 10.21 & 4.83 \\
\hline 5 & \multicolumn{2}{|c|}{ Varians } & \multicolumn{2}{|c|}{5.5225} & 0.1089 & 104.244 & 23.329 \\
\hline 6 & \multicolumn{2}{|c|}{ Skor maksimal } & \multicolumn{2}{|c|}{19.88} & 4.05 & 140 & 48.22 \\
\hline 7 & \multicolumn{2}{|c|}{ Skor Minimal } & \multicolumn{2}{|c|}{11.15} & 2.82 & 102 & 31.95 \\
\hline 8 & \multicolumn{2}{|c|}{ Range } & \multicolumn{2}{|c|}{8.73} & 1.23 & 38 & 16.27 \\
\hline \multirow{2}{*}{ No } & \multirow{2}{*}{\multicolumn{2}{|c|}{ Analisis Data }} & \multicolumn{5}{|c|}{ Variabel } \\
\hline & & & \multicolumn{2}{|c|}{$\mathrm{X} 1$} & $\mathrm{X} 2$ & X3 & $\mathrm{Y}$ \\
\hline 1 & $\mathrm{Ra}$ & -rata & & & 3.53 & 117.89 & 39.78 \\
\hline 2 & Mc & & - & & - & 102 & - \\
\hline 3 & $\mathrm{Me}$ & ian & & & 3.54 & 116 & 39.725 \\
\hline 4 & Sta & dar Deviasi & 2. & & 0.33 & 10.21 & 4.83 \\
\hline 5 & $\mathrm{Va}$ & ans & & 225 & 0.1089 & 104.244 & 23.329 \\
\hline 6 & Sk & maksimal & & & 4.05 & 140 & 48.22 \\
\hline 7 & Sk & Minimal & & & 2.82 & 102 & 31.95 \\
\hline 8 & $\mathrm{Ra}$ & & 8. & & 1.23 & 38 & 16.27 \\
\hline & & 85.5 & & 4 & & & $86 \%$ \\
\hline & & 90.5 & & 4 & & & $100 \%$ \\
\hline & & & & 28 & & $0 \%$ & \\
\hline
\end{tabular}

Data yang disajikan pada tabel di atas memperlihatkan sebaran skor Fleksibilitas pergelangan tangan yang terbagi dalam Lima kelompok. Berdasarkan data pada tabel di atas, dapat digambarkan penyebaran skor Fleksibilitas pergelangan tangan dalam 
bentuk histogram frekuensi yang diperlihatkan pada gambar berikut.

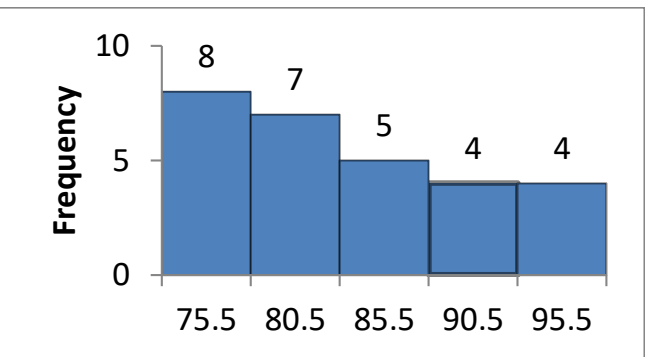

Gambar 2. Histogram Frekuensi Skor Fleksibilitas pergelangan tangan

Distribusi frekuensi skor Koordinasi mata tangan dari 28 responden diperlihatkan dalam tabel berikut.

Tabel 2. Distribusi Frekuensi Skor Koordinasi Mata Tangan

\begin{tabular}{|c|c|c|c|c|c|}
\hline \multirow{2}{*}{$\begin{array}{l}\text { Interva } \\
1\end{array}$} & \multicolumn{2}{|c|}{ Batas Interval } & \multirow{2}{*}{$\begin{array}{l}\text { Frekuens } \\
\text { i }\end{array}$} & \multirow{2}{*}{$\begin{array}{l}\text { Frekuensi } \\
\text { Relatif } \\
(\%)\end{array}$} & \multirow{2}{*}{$\begin{array}{l}\text { Frekuensi } \\
\text { Komulatif } \\
(\%)\end{array}$} \\
\hline & $\begin{array}{l}\text { Bawa } \\
\mathrm{h} \\
\end{array}$ & $\begin{array}{l}\text { Ata } \\
\mathrm{s}\end{array}$ & & & \\
\hline $\begin{array}{ll}10 & - \\
11 & \end{array}$ & 9.5 & 12 & 1 & $4 \%$ & $4 \%$ \\
\hline $\begin{array}{ll}12 & - \\
13 & \\
\end{array}$ & 11.5 & 14 & 8 & $29 \%$ & $32 \%$ \\
\hline $14-15$ & 13.5 & 16 & 12 & $43 \%$ & $75 \%$ \\
\hline $\begin{array}{ll}16 & - \\
17 & \end{array}$ & 15.5 & 18 & 6 & $21 \%$ & $96 \%$ \\
\hline $\begin{array}{ll}18 & - \\
19 & \end{array}$ & 17.5 & 20 & 1 & $4 \%$ & $100 \%$ \\
\hline Jumlah & & & 28 & $100 \%$ & \\
\hline
\end{tabular}

\begin{tabular}{|l|l|l|l|}
\hline Interval & Frekuensi & $\begin{array}{l}\text { Frekuensi } \\
\text { Relatif }(\%)\end{array}$ & $\begin{array}{l}\text { Frekuensi } \\
\text { Komulatif }(\%)\end{array}$ \\
\hline 4 & 8 & $28.57 \%$ & $28.57 \%$ \\
\hline 5 & 12 & $42.86 \%$ & $71.43 \%$ \\
\hline 6 & 8 & $28.57 \%$ & $100 \%$ \\
\hline Jumlah & 28 & $100 \%$ & \\
\hline
\end{tabular}

Data yang disajikan pada tabel di atas memperlihatkan sebaran skor koordinasi mata tangan yang terbagi dalam lima kelompok. Berdasarkan data pada tabel di atas, dapat digambarkan penyebaran skor koordinasi mata tangan dalam bentuk histogram frekuensi yang diperlihatkan pada gambar berikut.

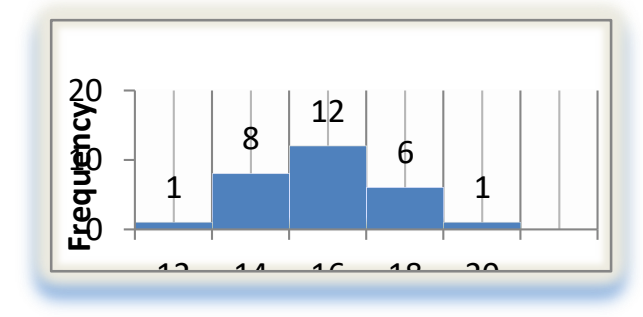

Gambar 3. Histogram Frekuensi Skor Koordinasi Mata Tangan

2. rasa percaya diri

Distribusi frekuensi skor Rasa Percaya Diri dari 30 responden diperlihatkan dalam tabel berikut.

Tabel 3. Distribusi Frekuensi Skor Rasa Percaya Diri

\begin{tabular}{|c|c|c|c|c|c|c|}
\hline \multirow[b]{2}{*}{ nterval } & \multicolumn{2}{|c|}{$\begin{array}{l}\text { Bat } \\
\text { as interval }\end{array}$} & \multirow[b]{2}{*}{$\begin{array}{l}\text { rekuen } \\
\text { si }\end{array}$} & \multirow{2}{*}{$\begin{array}{l}\text { rekuensi } \\
\text { elatif } \\
(\%) \\
\end{array}$} & \multirow{2}{*}{\multicolumn{2}{|c|}{$\begin{array}{l}\text { Fr } \\
\text { ekuensi } \\
\text { omulatif } \\
(\%) \\
\end{array}$}} \\
\hline & awah & tas & & & & \\
\hline $\begin{array}{l}43 \\
155\end{array}$ & 42.5 & 55.5 & & $\%$ & $\%$ & 3 \\
\hline $\begin{array}{l}56 \\
168\end{array}$ & 55.5 & 68.5 & & $\%$ & $\%$ & 3 \\
\hline $\begin{array}{l}69 \\
181\end{array}$ & 68.5 & 81.5 & & $3 \%$ & $\%$ & 16 \\
\hline $\begin{array}{l}82 \\
194\end{array}$ & 81.5 & 94.5 & & $7 \%$ & $\%$ & 43 \\
\hline $\begin{array}{l}95 \quad- \\
207\end{array}$ & 94.5 & 07.5 & 1 & $7 \%$ & $\%$ & 80 \\
\hline $\begin{array}{l}08 \\
220\end{array}$ & 07.5 & 20.5 & & $0 \%$ & $0 \%$ & 10 \\
\hline & Jumlah & & 0 & $00 \%$ & & \\
\hline
\end{tabular}

Data yang disajikan pada tabel di atas memperlihatkan sebaran skor Percaya Diri yang terbagi dalam enam kelompok. Berdasarkan data pada tabel di atas, dapat digambarkan penyebaran skor kekuatan Percaya Diri dalam bentuk histogram frekuensi yang diperlihatkan pada gambar : 


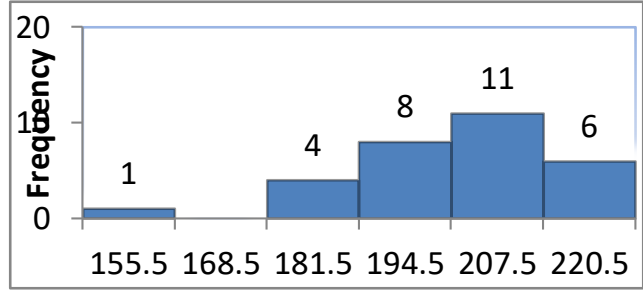

\section{Gambar 4. Histogram Frekuensi Skor Rasa Percaya Diri}

Distribusi frekuensi skor rasa Shooting Freethrow dari 28 responden diperlihatkan dalam tabel berikut.

tabel 4.4: distribusi frekuensi skor shooting freethrow

Data yang disajikan pada tabel di atas memperlihatkan sebaran skor Shooting Freethrow yang terbagi dalam tiga kelompok. Berdasarkan data pada tabel di atas, dapat digambarkan penyebaran skor shooting freethrow dalam bentuk histogram frekuensi yang diperlihatkan pada gambar berikut.

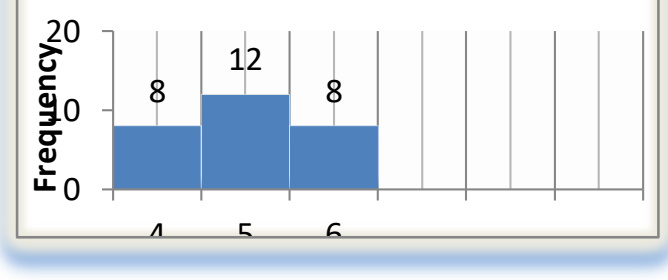

\section{Gambar 5. Diagram Frekuensi Skor Freethrow}

Nilai korelasi yang diperoleh menunjukkkan bahwa hubungan Fleksibilitas Pergelangan Tangan (X1), Koordinasi MataTangan (X2), Percaya diri (X3) dengan Shooting Freethrow (Y) masuk kategori kuat (berada pada interval $0,6 \quad-0,8$ ). Untuk menguji signifikansi hubungan Fleksibilitas Pergelangan Tangan (X1), Koordinasi MataTangan (X2), Percaya diri (X3) Dengan Shooting Freethrow (Y) digunakan uji F. Nilai $F$ hitung dari hasil perhitungan diperoleh sebesar 28,799. Untuk $\mathrm{n}=28$ diperoleh nilai $\mathrm{F}$ tabel dengan $\mathrm{db} 1=3$ dan $\mathrm{db} 2=26$ adalah 2,725. Karena $\mathrm{F}$ hitung
$(=28,7992) \quad>\mathrm{F}$ tabel $(=2,725)$ maka $\mathrm{H}_{0}$ ditolak atau nilai sig $(0,000)<0,05$, maka $\mathrm{H}_{0}$ ditolak. Artinya sumbangan atau kontribusi Fleksibilitas Pergelangan Tangan, Koordinasi Mata-Tangan, dan Percaya diri secara bersama-sama terhadap Shooting Freethrow bermakna (signifikan).

\section{KESIMPULAN}

Sesuai dengan permasalahan yang ada dan data yang telah dikumpulkan, serta hasil analisis yang telah dilakukan, akhirnya peneliti mengambil kesimpulan sebagai berikut :Terdapat hubungan yang signifikan antara Fleksibilitas Pergelangan Tangan dengan Shooting Freethrow dalam cabang olahraga bola basket. Terdapat hubungan yang signifikan antara Koordinasi MataTangan dengan Shooting Freethrow dalam cabang olahraga bola basket Terdapat hubungan yang signifikan antara percaya diri dengan Shooting Freethrow dalam cabang olahraga bola basket Terdapat hubungan secara bersama-sama yang signifikan antara, Fleksibilitas Pergelangan Tangan, koordinasi mata-tangan dan percaya diri pada Shooting Freethrow dalam cabang olahraga bola basket.

Hasil penelitian ini memberikan implikasi bahwa salah satu upaya untuk meningkatkan keterampilan shooting freethrow dalam permainan bola Basket adalah dengan meningkatkan fleksibilitas pergelangan tangan, koordinasi mata-tangan dan percaya diri. Tetapi tetap harus diingat bahwa masih ada faktor lain yang berpengaruh terhadap keterampilan shooting freethrow dalam Bola basket, sehingga perlu adanya penelitian lebih lanjut lagi.

\section{DAFTAR PUSTAKA}

Husdarta, .Psikologi olahraga, (Bandung: alfabeta, 2011), 
Ismayati, Tes dan Pengukuran Olahraga. Surakarta : sebelas maret University. (2006).

John oliver. Dasar Dasar Bola Basket.Bandung. Pakaraya (2002)

Komarudin, Psikologi olahraga. Bandung. Rosda Karya. (2013)

Lee $\mathrm{H}$ Rose winning basketball fundamentals (Human Kinetics Publishers Inc. 2013).

Richard, Schmidt, A Motor Learning and Performance (champaign : human kinetics publisher inc)

Rismayadi, Alen, Buku Bola Basket. Bandung : STKIP PASUNDAN CIMAHI. (2009).
Rismayadi, Alen , Efektifitas model latihan menggunakan rintangan dan tidak menggunakan rintangan terhadap hasil latihan keterampilan lay up shoot dalam permainan bola basket siswa smp negeri 7. Bandung. FPOK. Universitas pendidikan Indonesia (2009).

Setyobroto, Sudibyo. Psikologi Olahraga. Jakarta: Uiversitas Negeri Jakarta. 2002

Tangkudung, James. Kepelatihan Olahraga. (Jakarta : Cerdas Jaya, 2012),

Wishnubroto. Widarso. Sukses Membangun Rasa Percaya Diri "Self Confidence" Jakarta, Gramedia. (2005). 